\title{
Lixiviação de nitrogênio afetada pela forma de aplicação da uréia e manejo dos restos culturais de aveia em dois solos com texturas contrastantes
}

\author{
Nitrogen leaching as affected by urea aplication \\ method and oat residue management in soils \\ with contrasting textures
}

Luís Sangoi ${ }^{1}$ Paulo Roberto Ernani ${ }^{2}$ Vanderlei Adilson Lech $^{3}$ Clair Rampazzo ${ }^{4}$

\section{RESUMO}

A lixiviação de nitrato é um dos principais processos responsáveis pela perda de nitrogênio do solo. O presente trabalho objetivou avaliar o efeito da forma de aplicação da uréia e do manejo dos resíduos culturais de aveia preta sobre as perdas de $N$ por lixiviação, em solos com diferentes conteúdos de argila e matéria orgânica (MO). Dois experimentos foram conduzidos em laboratório, num Nitossolo Vermelho (NV) e num Neossolo Quartzarênico (NQ), contendo 520 e $50 \mathrm{~g} . \mathrm{dm}^{-3}$ de argila, respectivamente. Os tratamentos consistiram da combinação de três sistemas de manejo da cobertura de inverno (sem palha, palha aplicada na superficie e palha incorporada no solo) e três formas de aplicação do adubo nitrogenado (sem $N, N$ na superficie e $N$ incorporado). Utilizou-se palha de aveia preta, na quantidade equivalente a $4 \mathrm{Mg} \cdot \mathrm{ha}^{-1}$. As doses de $\mathrm{N}$ foram de 129 e $90 \mathrm{mg} . \mathrm{kg}^{-1}$ de solo para o $N V$ e $N Q$, respectivamente, na forma de uréia sólida. A lixiviação foi aproximadamente quatro vezes maior no $\mathrm{NV}$ do que no $N Q$ quando não se aplicou nitrogênio. A aplicação superficial da uréia propiciou menor lixiviação de $N$ do que a incorporação, nos dois solos estudados. A adição da palha de aveia sobre a superficie do solo aumentou a lixiviação de $N$ no $N V$, independentemente do manejo da adubação nitrogenada. A aplicação do $N$ na superficie e a incorporação dos resíduos de aveia ao solo mantiveram maior quantidade de nitrogênio mineral $\left(\mathrm{N}-\mathrm{NO}^{-1}+\mathrm{N}-\mathrm{NH} \mathrm{H}^{+1}\right)$ remanescente no $\mathrm{NV}$. A quantidade de $N$ remanescente foi maior no $N V$ do que no $N Q$.

Palavras-chave: nitrato, lixiviação, dinâmica de nitrogênio, residuos culturais

\section{ABSTRACT}

Nitrate leaching is normally the most important process affecting nitrogen losses in the soil. This experiment aimed to evaluate the effect of methods of urea application and different management strategies of black oat residue on $N$ leaching in soils with different clay and organic matter contents. Two laboratory studies were conducted using two kinds of soil: an UDULT (UD) and a PSAMENT (PS), containing 520 and $50 \mathrm{~g} . \mathrm{dm}^{-3}$ of clay, respectively. Treatments included a combination of three management systems of oat residue (without straw, superficial straw and incorporated straw) and three methods of nitrogen application (without $N$, superficial $N$ and incorporated $\mathrm{N}$ ). Oat straw was applied at a rate of $4 \mathrm{Mg} . \mathrm{ha}$ ${ }^{I}$ and nitrogen at rates of 129 and $90 \mathrm{mg}^{\mathrm{kg}} \mathrm{kg}^{-1}$ for the UD and $P S$, respectively, as urea. When no $N$ was applied, leaching values were approximately four times larger in the UD than in the PS. Application of urea to the soil surface decreased the

${ }^{1}$ Engenheiro Agrônomo, PhD., Professor da Universidade do Estado de Santa Catarina (UDESC), CP 281, 88520-000, Lages - SC, Brasil. Bolsista do CNPq. E-mail: a21s@cav.udesc.br

${ }^{2}$ Engenheiro Agrônomo, PhD., Professor da UDESC. Bolsista do CNPq. E-mail: a2pre@cav.udesc.br.

${ }^{3}$ Engenheiro Agrônomo, aluno do Curso de Mestrado em Ciência do Solo da UDESC. Bolsista da CAPES. 
amount of $N$ leached when compared to incorporation of urea, in both soils. There was higher $N$ leaching when oat straw was kept at the soil surface than with its incorporation in the UD, regardless of nitrogen management. Superficial $N$ application and oat straw incorporation yielded higher quantities of mineral remaining nitrogen $\left(\mathrm{N}-\mathrm{NO}_{3}^{-1}+\mathrm{N}-\mathrm{NH}_{4}^{+1}\right)$ in the soil. The remaining nitrogen values were greater in the UD than in the $P S$ at the end of the experimental period.

Key words: nitrate, leaching, nitrogen dynamics, crop residue

\section{INTRODUÇÃO}

$\mathrm{O}$ nitrato $\left(\mathrm{NO}_{3}{ }^{-1}\right)$ é a forma mineral de nitrogênio predominante nos solos sem restrição de oxigênio. Devido ao predomínio de cargas negativas na camada arável, a sua adsorção eletrostática é insignificante. Desta forma, o nitrato permanece na solução do solo, o que favorece sua lixiviação no perfil para profundidades inexploradas pelas raízes (CERETTA \& FRIES, 1997).

A lixiviação de nitrato é considerada a principal perda do $\mathrm{N}$ disponível às plantas (ERREBHI et al., 1998). Ela é influenciada diretamente pelos fatores que determinam o fluxo de água no solo e pela concentração de $\mathrm{NO}_{3}^{-}$na solução (WHITE, 1987). Fatores como sistema de preparo do solo, tipo de solo e forma de aplicação dos fertilizantes nitrogenados, podem influenciar tanto o fluxo de água quanto a concentração de nitrato na solução do solo.

THOMAS et al. (1973) e MUZILLI (1983) observaram menor concentração de nitrogênio mineral no solo quando o milho estava sendo cultivado no sistema de plantio direto (SPD) do que no sistema convencional (SPC). Os autores atribuíram parcialmente este fato à maior movimentação descendente da água através dos macroporos no PD, ocasionando lixiviação de nitrato para as camadas mais profundas neste sistema de cultivo. A menor evaporação de água devido à maior cobertura de solo propiciada pelos restos de cultura sobre a superfície do solo no PD, também pode favorecer o movimento descendente de nitrato via macroporos. Por outro lado, BAYER \& MIELNICZUK (1997) observaram maior lixiviação de nitrogênio no sistema de semeadura convencional, devido à maior decomposição da $\mathrm{MO}$ e dos resíduos culturais incorporados ao solo propiciados por este sistema, em relação ao SPD.

O tipo de solo pode ter grande influência na magnitude do processo de lixiviação. Solos argilosos possuem maior capacidade de retenção de nitrogênio, principalmente na forma de $\mathrm{NH}_{4}^{+}$, do que solos arenosos. A maior capacidade de armazenamento de água dos solos argilosos reduz a percolação da água pelo perfil e, consequentemente, o arraste de nitrato para camadas inferiores do solo (BORTOLINI, 2000; CAMARGO et al., 1989). Além da textura, o conteúdo de matéria orgânica também pode interferir na lixiviação de nitrato, em função da maior disponibilidade de nitrogênio decorrente da decomposição da $\mathrm{MO}$, principalmente quando a área não está sendo cultivada.

Outro fator que pode influenciar as perdas de $\mathrm{N}$ por lixiviação é a forma de aplicação do adubo nitrogenado. Perdas de amônia (NH ) por volatilização são potencialmente maiores quand̆ os fertilizantes amoniacais e amídicos são aplicados em superfície e em solos secos (BOUWEESTER et al., 1985). Além disso, a volatilização pode ser intensificada quando os resíduos culturais ficam sobre a superfície do solo. Desta forma, a lixiviação de $\mathrm{N}$ pode ser maior quando se incorpora o adubo nitrogenado devido à redução na possibilidade de perdas de $\mathrm{N}$ por volatilização, resultando em maiores concentrações deste nutriente na solução do solo.

O conhecimento das reações que interferem na dinâmica do nitrogênio é fundamental para subsidiar recomendações técnicas eficientes sobre o manejo da adubação nitrogenada às plantas, específicas para cada situação de lavoura. O presente trabalho objetivou avaliar o efeito do método de aplicação da uréia e do manejo de resíduos culturais de aveia preta sobre as perdas de $\mathrm{N}$ por lixiviação, em solos com diferentes conteúdos de argila e matéria orgânica.

\section{MATERIAL EMÉTODOS}

O trabalho foi conduzido no laboratório de Fertilidade do Solo da Faculdade de Agronomia da Universidade do Estado de Santa Catarina (UDESC), em Lages, SC, no ano de 2000. Foram usados dois solos: um Nitossolo Vermelho (NV), coletado em área de campo nativo de Lages, no Planalto Catarinense, com $48 \mathrm{~g} . \mathrm{dm}^{-3}$ de matéria orgânica (MO) e $520 \mathrm{~g} \cdot \mathrm{dm}^{-3}$ de argila; e um Neossolo Quartzarênico (NQ) proveniente do município de Jaguaruna, localizado no litoral sul do estado de Santa Catarina, com $8 \mathrm{~g} \cdot \mathrm{dm}^{-3}$ de matéria orgânica e $50 \mathrm{~g} . \mathrm{dm}^{-3}$ de argila. Aproximadamente 2 meses antes da aplicação dos tratamentos, o pH em água dos solos foi elevado até 6,0 pela aplicação de calcário dolomítico.

Os tratamentos consistiram da combinação de três sistemas de manejo de resíduos de cobertura do solo (sem palha, palha aplicada na superfície e palha incorporada ao solo) com três sistemas de manejo do adubo nitrogenado (sem $\mathrm{N}, \mathrm{N}$ na superfície e $\mathrm{N}$ incorporado ao solo). Utilizou-se palha de aveia preta, coletada quando a cultura se encontrava em 
florescimento, na quantidade equivalente a $4 \mathrm{Mg} \mathrm{ha}^{-1}$. As doses de $\mathrm{N}$ utilizadas foram de 129 e $90 \mathrm{mg} . \mathrm{kg}^{-1} \mathrm{de}$ solo para o NV e NQ, respectivamente, totalizando aproximadamente $190 \mathrm{mg}$ de $\mathrm{N}$ por unidade experimental. A fonte de $\mathrm{N}$ aplicada foi a uréia. Os tratamentos foram arranjados no delineamento completamente casualizado, com três repetições.

As unidades experimentais foram constituídas por colunas de lixiviação, formadas por canos de PVC com $30 \mathrm{~cm}$ de altura e $10 \mathrm{~cm}$ de diâmetro. Cada unidade experimental continha $1,47 \mathrm{~kg}$ de solo argiloso ou $2,1 \mathrm{~kg}$ de solo arenoso, perfazendo $1900 \mathrm{~cm}^{3}$ de solo em base seca. Foram deixados $5 \mathrm{~cm}$ da parte superior de cada coluna sem solo, para possibilitar a adição da solução de percolação. A parte inferior das mesmas foi vedada com uma tampa de PVC na qual se fez um orifício de $3 \mathrm{~mm}$ de diâmetro, para permitir a saída da solução percolada.

Semanalmente, durante 12 semanas, adicionaram-se $300 \mathrm{ml}$ de água destilada sobre cada coluna de lixiviação, no período de uma hora. A primeira adição foi feita três dias após a aplicação dos tratamentos. No dia seguinte à adição da água destilada, coletou-se a solução percolada. Nela mediu-se o volume e determinou-se a quantidade de amônio + nitrato, por arraste de vapores, em aparelho semi-micro-Kjeldahl, de acordo com TEDESCO et al. (1995). A quantidade total de nitrogênio lixiviada durante os três meses foi obtida pelo somatório das quantidades lixiviadas em cada semana. Ao final do experimento, coletaram-se amostras de solo e quantificou-se a quantidade de amônio + nitrato remanescente, extraídos com $\mathrm{KCl}$ 1mol. $\mathrm{L}^{-1}$, seguindo metodologia descrita em TEDESCO et al. (1995).

Os dados obtidos foram avaliados estatisticamente por meio de análise de variância, seguindo o modelo descrito em RIBOLDI (1993). A análise estatística foi realizada individualmente para cada solo, considerando o esquema fatorial $3 \times 3$. A magnitude dos efeitos dos tratamentos aplicados frente ao erro experimental foi testada com o teste F. Os valores de F obtidos para efeitos principais e interações foram considerados significativos ao nível de 5\% $(\mathrm{P}<0,05)$. Quando alcançada significância estatística, a comparação de médias entre tratamentos foi realizada através do teste Duncan, a $5 \%$ de probabilidade de erro.

\section{RESULTADOS E DISCUSSÃO}

Os efeitos da forma de aplicação da uréia e do tipo de manejo da palha de aveia sobre a lixiviação de $\mathrm{N}$ variaram com o tipo de solo. No Neossolo Quartzarênico, a interação entre estes dois fatores influenciou a quantidade total de nitrogênio lixiviada (Tabela 1). Neste solo, a lixiviação aumentou com a aplicação da adubação nitrogenada, e foi mais intensa quando a uréia foi incorporada do que quando aplicada sobre a superfície do solo. No tratamento sem a aplicação de N, a lixiviação aumentou com a adição da palha, principalmente quando os resíduos foram mantidos sobre a superfície do solo. Isto provavelmente ocorreu pela contribuição do nitrogênio proveniente da aveia, que foi mineralizado pelos microrganismos durante as 12 semanas do experimento (Tabela 1).

Quando a uréia foi incorporada no Neossolo Quartzarênico, a lixiviação foi menor com a incorporação do resíduo do que com sua ausência ou a manutenção na superfície (Tabela 1). Isto provavelmente ocorreu porque a incorporação da palha favorece o crescimento da população microbiana no solo, normalmente baixa nos solos arenosos do litoral sul catarinense. Com isto, pode ter havido imobilização

Tabela 1 - Manejo dos restos culturais de aveia preta, forma de aplicação da adubação nitrogenada e a quantidade total de $\mathrm{N}$ lixiviada num Neossolo Quartzarênico. Lages, SC, 2000.

\begin{tabular}{|c|c|c|c|}
\hline \multirow[b]{2}{*}{ Manejo da palha } & \multicolumn{3}{|c|}{ Manejo do nitrogênio } \\
\hline & Sem N & $\mathrm{N}$ incorporado & $\mathrm{N}$ superfície \\
\hline \multicolumn{4}{|c|}{ - } \\
\hline Sem palha & C $12,4 c^{*}$ & A 59,4 a & B 43,2 a \\
\hline Palha incorporada & C 19,3 b & A $51,1 \mathrm{~b}$ & B 43,6 a \\
\hline Palha superficial & $\mathrm{C} 28,8 \mathrm{a}$ & A 65,2 a & B $31,6 \mathrm{~b}$ \\
\hline
\end{tabular}


temporária de parte do $\mathrm{N}$ aplicado via fertilizante. Quando a uréia foi aplicada sobre a superfície do solo, a manutenção da palha em superfície reduziu a quantidade de $\mathrm{N}$ lixiviada, em relação ao tratamento com palha incorporada. Esta diminuição provavelmente ocorreu em função do aumento da volatilização de amônia, que é favorecido pela presença de cobertura vegetal superficial, reduzindo o contato do fertilizante com o solo (CERETTA, 1997).

No Nitossolo Vermelho, os efeitos simples do manejo da palha e do nitrogênio afetaram significativamente a quantidade de $\mathrm{N}$ lixiviada, não havendo
HOWARD \& ESSINGTON, 1998; LARA CABEZAS et al., 2000). Alta lixiviação de N, principalmente quando o fertilizante foi incorporado, também foi observada por CAMARGO et al., (1997) num solo argiloso.

Comparando-se os valores numéricos obtidos nos dois solos, verifica-se que a quantidade de nitrogênio lixiviada onde não foi aplicado $\mathrm{N}$ foi aproximadamente quatro vezes maior no Nitossolo Vermelho do que no Neossolo Quartzarênico (Tabelas 1 e 2). Isto demonstra a grande capacidade que os solos argilosos, principalmente aqueles com alto teor de carbono, têm em disponibilizar N para a solução do solo.

Tabela 2 - Manejo dos restos culturais de aveia preta, forma de aplicação da adubação nitrogenada e a quantidade de $\mathrm{N}$ lixiviada num Nitossolo Vermelho. Lages, SC, 2000.

\begin{tabular}{|c|c|c|c|}
\hline \multicolumn{2}{|c|}{ Manejo da palha } & \multicolumn{2}{|c|}{ Manejo do nitrogênio } \\
\hline & ------------ & 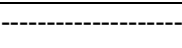 & \\
\hline Sem palha & $107,8 \mathrm{ab}^{*}$ & Sem N & $83,3 \mathrm{c}$ \\
\hline Palha incorporada & $103,9 \mathrm{~b}$ & $\mathrm{~N}$ incorporado & $130,5 \mathrm{a}$ \\
\hline Palha superfície & $118,1 \mathrm{a}$ & $\mathrm{N}$ superfície & $116,3 \mathrm{~b}$ \\
\hline
\end{tabular}

* Médias sucedidas por mesma letra minúscula na coluna não diferem significativamente pelo teste Duncan, a 5\% de probabilidade de erro.

interação entre os dois fatores. A lixiviação foi maior quando a palha foi mantida sobre o solo do que quando foi incorporada (Tabela 2). A maior lixiviação de N observada com a manutenção de palha na superfície pode ser explicada por melhores condições de temperatura e umidade, as quais favorecem a atividade microbiana, que assim mineraliza mais matéria orgânica (FRIES, 1997; ERNANI et al., 2002) e transforma mais $\mathrm{NH}^{+}$para $\mathrm{NO}$-, tornando o nitrogênio mais facilmente lixiviável. Além disto, a incorporação de restos culturais com alta relação $\mathrm{C} / \mathrm{N}$ num solo com intensa atividade microbiana, como o nitossolo vermelho avaliado, pode ter estimulado a imobilização temporária de nitrogênio (LECH, 2001). Com isto, menos nitrato foi lixiviado.

A quantidade lixiviada de $\mathrm{N}$ no Nitossolo Vermelho aumentou com a adição de uréia, sendo maior quando esta foi incorporada ao solo. O aumento de lixiviação obtido com a incorporação do N, em relação à aplicação superficial, confirmou os resultados obtidos no neossolo quartzarênico e também os reportados por SAMPAIO \& SALCEDO (1993), onde a mineralização do $\mathrm{N}$ nativo dobrou com a incorporação da uréia ao solo. Além disto, as perdas de NH por volatilização são potencialmente maiores quanđo os fertilizantes nitrogenados amoniacais são aplicados em superfície, principalmente em condições com deficiência de umidade (BOUWMEESTER et al., 1985;
Os manejos da palha e do nitrogênio influenciaram a quantidade de $\mathrm{N}$ remanescente somente no solo argiloso (Tabela 3). Quando a palha foi incorporada, observou-se mais $\mathrm{N}$ remanescente no solo do que nos tratamentos sem palha ou com palha na superfície. Isso pode ter ocorrido devido à incorporação da palha fornecer carbono facilmente oxidável que serve de energia para a população microbiana (FRIES, 1997), resultando em aumento da atividade e população no solo. Desta forma, parte do $\mathrm{N}$ pode ter sido incorporado temporariamente à massa celular microbiana, resultando na redução do seu conteúdo mineral no solo. A conseqüência disto foi a redução da quantidade de $\mathrm{N}$ lixiviada a curto prazo (Tabela 2) e o aumento da quantidade de $\mathrm{N}$ remanescente no solo ao final de doze semanas (Tabela 3), em relação ao tratamento com palha na superfície.

Observou-se menor quantidade de nitrogênio remanescente no solo argiloso quando a uréia foi incorporada ao solo do que com a aplicação superficial (Tabela 3). Tal comportamento pode ser atribuído às maiores perdas por lixiviação verificadas quando se incorporou o N (Tabela 2) e à incorporação do N na massa microbiana. Os altos teores de $\mathrm{N}$ mineral encontrados neste solo após três meses da aplicação dos tratamentos, reafirmam a grande capacidade de suprimento de $\mathrm{N}$ a partir da mineralização do $\mathrm{N}$ presente na 
Tabela 3 - Manejo dos restos culturais de aveia preta, forma de aplicação da adubação nitrogenada e a quantidade de nitrogênio mineral remanescente $\left(\mathrm{N}-\mathrm{NO}_{3}^{-1}+\mathrm{N}-\mathrm{NH}_{4}{ }^{+1}\right)$ em dois solos. Lages, $\mathrm{SC}, 2000$.

\begin{tabular}{lcc}
\hline & Nitossolo Vermelho & Neossolo quartzarênico \\
\hline Manejo da palha & $----------~ N$ remanescente $\left(\mathrm{mg} \mathrm{kg}^{-1}\right)$---------- \\
Sem palha & $85,6 \mathrm{~b}^{*}$ & $6,03 \mathrm{NS} * *$ \\
Palha incorporada & $96,8 \mathrm{a}$ & 5,82 \\
Palha superfície & $84,9 \mathrm{~b}$ & 6,11 \\
Manejo do nitrogênio & & $6,05 \mathrm{NS} *$ \\
Sem N & $79,6 \mathrm{~b}$ & 5,69 \\
N incorporado & $76,0 \mathrm{~b}$ & 6,24 \\
N superfície & $111,1 \mathrm{a}$ & \\
\hline
\end{tabular}

* Médias sucedidas por mesma letra minúscula na coluna, para cada sistema de manejo, não diferem significativamente pelo teste Duncan, a 5\% de probabilidade de erro.

NS** Diferenças entre médias não significativas estatisticamente pelo teste Duncan, a 5\% de probabilidade de erro.

matéria orgânica deste Nitossolo Vermelho do Planalto Catarinense. Os altos valores de $\mathrm{N}$ remanescente no solo argiloso após o término das lixiviações também se devem ao fato de que as amostras de solo foram secas previamente à determinação. Durante a secagem, provavelmente parte da matéria orgânica humificada do solo foi mineralizada, liberando nitrogênio.

O manejo da adubação nitrogenada e da palha não influenciaram a quantidade total de $\mathrm{N}$ remanescente no solo arenoso (Tabela 3), cujos valores finais foram muito menores que os do solo argiloso. Isto provavelmente ocorreu devido à grande lixiviação verificada nesse solo, estimulada pela baixa CTC. Assim, a maior parte do N permaneceu na solução do solo, sendo carregada pelos fluxos de água. Além disso, a menor capacidade de armazenamento de água deste solo, em relação ao argiloso, deve ter contribuído para exaurir o $\mathrm{N}$ adicionado.

Os resultados reforçam a observação feita por ERNANI (1999) e BORTOLINI (2000) de que em solos arenosos, que apresentam maior facilidade de lixiviação de nitrato, devem receber fertilização nitrogenada em maior quantidade e número de aplicações, do que solos argilosos. Neste sentido, SANCHEZ (2000), verificou que $88 \%$ do $\mathrm{N}$ aplicado para a alface não foi recuperado num solo com mais de $950 \mathrm{~g} \cdot \mathrm{kg}^{-1} \mathrm{de}$ areia, indicando grande perda de $\mathrm{N}$ através da lixiviação. Os baixos valores de $\mathrm{N}$ remanescente no NQ ao final do experimento reforçam o conceito de que a adubação nitrogenada em solos arenosos deve ser realizada de forma mais criteriosa, devido à grande lixiviação, e à pequena contribuição do $\mathrm{N}$ proveniente da matéria orgânica.

\section{CONCLUSÕES}

Tanto no Nitossolo Vermelho quanto no Neossolo Quartzarênico, a magnitude das perdas de nitrogênio por lixiviação foi afetada pelo tipo de manejo dos restos culturais existentes na área e pela forma de aplicação do fertilizante nitrogenado.

A incorporação da uréia favoreceu as perdas por lixiviação, em relação a sua aplicação superficial, independentemente do teor de matéria orgânica e da classe textural do solo.

A manutenção de restos culturais de aveia preta em superfície estimulou a lixiviação de N no Neossolo Quartzarênico, quando a uréia foi incorporada ao solo.

A incorporação da palha de aveia diminuiu a lixiviação de N no Nitossolo Vermelho, independentemente da forma de aplicação da uréia.

\section{REFERÊNCIAS BIBLIOGRÁFICAS}

BAYER, C; MIELNICZUK, J. Características químicas do solo afetadas por métodos de preparo e sistemas de cultura. Revista Brasileira Ciência do Solo, Viçosa, v.21, n.1, p. 105-112, 1997.

BORTOLINI, C.G. Eficiência do método de adubação nitrogenada em pré-semeadura do milho implantado em semeadura direta após aveia preta. 2000. 48f. Dissertação (Mestrado em Fitotecnia)- Universidade Federal do Rio Grande do Sul.

BOUWEESTER, R.J.B; VLEK, P.L.G; STUMPE, J. M. Effect of environmental factors on ammonia volatilization from a urea-fertilized soil. Soil Science Society of America Journal, Madison, v.49, n.2, p.376-381, 1985.

CAMARGO, P. B. et al. Destino do $\mathrm{N}$ de fertilizantes $-\mathrm{N}^{15}$ (uréia e aquamônia) aplicados na cultura da cana-de-açúcar. I. Deslocamento no solo. In: CONGRESSO BRASILEIRO DE CIÊNCIA DO SOLO, 22., 1989, Recife. Resumos... Recife : SBCS, 1989. p.70-71. 
CAMARGO, F. A. O; GIANELlO, C.; VIDOR, C. Potencial de mineralização do nitrogênio em solos do Rio Grande do Sul. Revista Brasileira Ciência do Solo, Viçosa, v.21, n.3, p.575579, 1997.

CERETTA, C.A. Manejo da adubação nitrogenada na sucessão aveia-milho, no sistema de plantio direto. In: FRIES, M.R; DALMOLIN, R.S.D. Atualização em recomendação de adubação e calagem: ênfase em plantio direto. Santa Maria : Pallotti, 1997. Cap.5. p.112-124.

CERETTA, C.A; FRIES, M.R. Adubação nitrogenada no sistema de plantio direto. In: NUERNBERG, N.J. Plantio direto: conceitos, fundamentos e práticas culturais. Sociedade Brasileira de Ciência do Solo, Núcleo Regional Sul, 1997. Cap.7, p.111-120.

ERNANI, P. R. Nutrição e produtividade de espécies vegetais em sistemas de plantio direto e convencional. In: REUNIÃO TÉCNICA CATARINENSE: MILHO \& FEIJÃO, Lages, 2., 1999. Resumos... Lages : UDESC/EPAGRI, 1999. v.1, p.19-30.

ERNANI, P.R; SANGOI, L; RAMPAZZO, C. Influência do método de aplicação da uréia e dos restos culturais de aveia preta na lixiviação de nitrogênio e no rendimento de matéria seca do milho. Revista Brasileira Ciência do Solo, v.25, prelo, 2002.

ERREBHI, M. et al. Patato yield response and nitrate leaching as influenced by nitrogen management. Agronomy Journal, v.90, n.1, p.10-15, 1998 .

FRIES, M.R. Microbiologia e matéria orgânica: recuperação pelo sistema plantio direto. In: FRIES, M.R; DALMOLIN, R.S.D. (Coord.). Atualização em recomendação de adubação e calagem: ênfase em plantio direto. Santa Maria : Pallotti, 1997. Cap.3, p.47-75.

HOWARD, D.D.; ESSINGTON, M.E. Effects of surface-applied limestone on the efficiency of urea-containing nitrogen sources for no-till corn. Agronomy Journal, Madison, v.90, n.3, p.523-528, 1998 .
LARA CABEZAS, W.A.R. et al. Balanço da adubação nitrogenada sólida e fluída de cobertura na cultura do milho, em sistema plantio direto no triângulo mineiro. Revista Brasileira de Ciência do Solo, Viçosa, v.24, n.2, p.363-376, 2000 .

LECH, V.A. Perdas de $\mathbf{N}$ e resposta do milho a adubação nitrogenada afetadas por sistemas de manejo dos restos culturais de aveia preta. 2001. 85f. Dissertação (Mestrado em Ciências do Solo) - Programa de Pós-Graduação em Agronomia, Universidade do Estado de Santa Catarina, Lages.

MUZZILI, O. A influência do sistema de plantio direto, comparado ao convencional, sobre a fertilidade da camada arável do solo. Revista Brasileira Ciência do Solo, Campinas, v.7, n.1, p.95-102, 1983.

RIBOLDI, J. Delineamentos experimentais de campo, Parte 2. Porto Alegre : Instituto de Matemática, UFRGS, 1993. 720p. (Cadernos de matemática e estatística.

SAMPAIO, E.V.S.B; SALCEDO, I.H. Mineralização e absorção por milheto do nitrogênio do solo, da palha de milho- $\left({ }^{15} \mathrm{~N}\right)$ e da uréia- $\left({ }^{15} \mathrm{~N}\right)$. Revista Brasileira Ciência do Solo, Viçosa, v.17, n.3, p.423-429, 1993.

SANCHEZ, A. C. Response of lettuce to water and nitrogen on sand and the potential for leaching of nitrate-N. Hort Science, Yuma, v. 35, n.1, p.73-77, 2000.

TEDESCO, M.J; VOLKWEISS, S.J; BOHNEN, H. Análise de solo, plantas e outros materiais. Porto Alegre : Faculdade de Agronomia, Departamento de Solos, UFRGS, 1995. 188p. (Boletim Técnico, 5).

THOMAS, G.W. et al. Effects of a killed sod mulch on nitrate movement and corn yield. Agronomy Journal, Madison, v.65, n.5, p.736-739, 1973.

WHITE, R.E. Leaching. In: WILSON, J. R. Advances in nitrogen cycling in agricultural ecosystems. Wallinggord : C.A.B. International, 1987. p.193-211. 